Société d'histoire de la révolution de 1848 et des

révolutions du XIXe siècle

$22 \mid 2001$

Autour de Décembre 1851

\title{
Sébastien LAURENT, Daniel Halévy. Du libéralisme au traditionalisme, Paris, Grasset, 2001, 599 p.
}

Jean-Yves Mollier

\section{OpenEdition}

Journals

Édition électronique

URL : http://journals.openedition.org/rh19/265

DOI : $10.4000 /$ rh 19.265

ISSN : $1777-5329$

Éditeur

La Société de 1848

Édition imprimée

Date de publication : 1 juin 2001

ISSN : 1265-1354

Référence électronique

Jean-Yves Mollier, « Sébastien LAURENT, Daniel Halévy. Du libéralisme au traditionalisme, Paris, Grasset, 2001, 599 p. », Revue d'histoire du XIXe siècle [En ligne], 22 | 2001, mis en ligne le 28 juin 2005, consulté le 22 septembre 2020. URL : http://journals.openedition.org/rh19/265 ; DOI : https://doi.org/10.4000/ rh19.265

Ce document a été généré automatiquement le 22 septembre 2020.

Tous droits réservés 


\title{
Sébastien LAURENT, Daniel Halévy. Du libéralisme au traditionalisme, Paris, Grasset, 2001, 599 p.
}

\author{
Jean-Yves Mollier
}

1 Publiée un an après avoir été soutenue à l'Institut d'études politiques de Paris, cette grande thèse -4 volumes dont 2 de correspondances inédites à l'origine -, s'appuie d'abord sur la lecture et le dépouillement d'archives jusqu'ici inconnues ou non autorisées à la consultation. La reconstitution du parcours singulier de Daniel Halévy, compagnon de Charles Péguy, qui, en 1940, refuse de se considérer comme juif, puis, en 1943-1944, estime qu'il faut traiter avec Hitler et qui, à son décès en 1962, était plutôt favorable au maintien de l'Algérie dans la France, y gagne en épaisseur et en solidité. La lecture de centaines de lettres inédites, conservées dans les fonds publics mais aussi les fonds privés - les archives Grasset pour les contrats et correspondances avec les auteurs, celles de Jean-Pierre Halévy pour le Journal tenu entre 1886 et 1940, etc. -, a constitué une véritable révélation dans la mesure où le personnage qui apparaissait à la lumière de ces documents n'était pas celui de la légende ou du souvenir dreyfusien. La publication, contestée mais suggestive, du livre de Simon Epstein cette année ${ }^{1}$, vient d'ailleurs renforcer l'intérêt de l'étude de Sébastien Laurent puisque l'on a, dans ce livre, tous les éléments de compréhension de ce que d'aucuns pourraient appeler, à la suite de Philippe Burrin, une dérive.

Connu par ses livres - Apologie pour notre passé (1910), Visite aux paysans du Centre (1921) et La Fin des notables (1930) ou La République des ducs (1937) -, Daniel Halévy fut aussi le talentueux directeur de la collection "les cahiers verts" chez Bernard Grasset, et l'animateur d'un dîner et d'un salon dans son domicile du quai de l'Horloge à Paris, qui renforcèrent son pouvoir sur les milieux intellectuels de l'entre-deuxguerres. Homme de culture, traducteur de Nietzsche, né dans une famille prestigieuse, mêlant les plus grands noms de la musique, des lettres et de l'Université, cet homme double, selon une terminologie à la mode, symbolisa longtemps la rencontre entre plusieurs univers - ou champs -, qui, autrefois, ne se fréquentaient pas. Passeur de 
culture et intermédiaire de talent, il joua chez Bernard Grasset le rôle tenu par Gustave Le Bon chez Flammarion auparavant ou par Théodule Ribot chez Alcan, voire Duruy chez Hachette sous le second Empire : celui d'un homme au pouvoir fait de discrétion et d'influence certaine sur le mouvement des idées. Annonçant par ce trait le Jean Paulhan de la maison Gallimard après 1945, il effraie Romain Rolland par son côté conservateur mais publie aussi bien des romans - Le Diable au corps de Radiguet -, que des essais, ce par quoi la collection des Cahiers verts demeure aujourd'hui connue. Banville, Berl, Bonnard, Drieu la Rochelle, Montherlant s'y illustrèrent mais également Mauriac, Maurois et Malraux, Chamson et Guéhenno, ce qui rend délicat tout jugement sur l'ensemble de l'activité du directeur de collection. Rétrospectivement toutefois, la lucidité de Romain Rolland parait remarquable, signe d'une prescience des ambiguïtés d'un personnage qui ne fascinait pas nécessairement tous ses interlocuteurs.

La biographie de Sébastien Laurent traverse ainsi deux siècles, cette fin du XIX ${ }^{\mathrm{e}}$ qui s'étend de l'affaire Dreyfus à la Grande guerre, et ce premier XXe siècle qui vient mourir à la fin du second conflit mondial. Dreyfusiste à l'origine, militant des universités populaires en 1900, péguyste qui s'éloigne cependant des Cahiers de la quinzaine et de son fondateur en 1910 - Notre Jeunesse est la réponse à l'Apologie pour notre passé et marque la rupture entre les deux hommes-, Halévy devient conservateur dès cette époque. Libéral en effet depuis sa jeunesse, quoiqu'il ait pu donner l'illusion de passer à gauche au temps du combat pour la révision, il le demeure toute sa vie, ce qui explique, à notre sens, sa dérive ou son passage au traditionalisme. Loin d'être un exemple isolé - ce que montre le livre de Simon Epstein -, son évolution vers la dénonciation de La République des comités en 1934, au moment où il fustige la gauche et refuse le Front populaire, annonce les phases suivantes de sa trajectoire : approbation de la révolution nationale, absence de toute solidarité envers la communauté juive - il ne se voit pas comme Juif puisque deux de ses grands-parents ne l'étaient pas -, compréhension vis-à-vis du IIIe Reich puis, plus tard, de l'Algérie Française. Si, en fin de volume, on ressent une sorte de malaise, ce n'est pas parce que l'auteur, Sébastien Laurent, aurait noirci sa peinture du personnage, mais, plus simplement parce que l'on saisit mieux tout ce que le dreyfusisme put comporter d'ambiguïtés en réunissant, pour une courte période - 1897-1899 essentiellement -, des tempéraments et des sensibilités que tout séparait par ailleurs. C'est le mérite de l'auteur de cette biographie exemplaire de l'avoir mis en relief et si le débat est aujourd'hui relancé sur cette période, ce n'est probablement pas inutile tant les évolutions de certains compagnons de route d'Alfred Dreyfus paraissent étonnantes.

\section{NOTES}

1. Simon EPSTEIN, Les Dreyfusards sous l'Occupation, Paris, Éditions Albin Michel, 2001. 